\title{
Revista Médica de Trujillo
}

Publicación oficial de la Facultad de Medicina de la Universidad Nacional de Trujillo - Perú

\section{Editorial}

\section{La vocación y la carrera médica}

\author{
Vocation and the medical career
}

La palabra vocación tiene un origen bastante gráfico y pertinente. Viene del latín vocatio -onis, acción de llamar. Y el diccionario registra como su primera acepción "Inspiración con que Dios llama a algún estado, especialmente al de la religión". La cuarta acepción es la que maneja la calle: "Inclinación a cualquier estado, profesión o carrera".

Pedro Lain Entralgo considera al hombre como un constante hacerse y en ese hacerse, a la vocación como un factor fundamental. Vocación es, dice el médico español, el quehacer que hace al hombre coincidir consigo mismo; a continuación dice que quien es traidor a su vocación vive en falso; más que vivir, en realidad, muere, no de muerte biológica si no de muerte biográfica (1).

Gregorio Marañón, otro médico paradigmático del siglo $X X$, reflexionó intensamente sobre la vocación y la Medicina. Fue también bastante radical en su enfoque. Habla de vocación y pseudovocaciones. Marañón considera que la vocación verdadera es aquella que sigue la línea de la vocación religiosa, es decir "que se vive como la llamada a una determinada causa a la que uno se entrega en cuerpo y alma y sin esperar ningún tipo de premio o reconocimiento", mientras que las pseudo- vocaciones provendrían de la atracción por el mero conocimiento científico o el apego a los logros económicos o sociales que conlleva el ejercicio de la Medicina (2).

Hay, obviamente, quienes pretenden conciliar. Miguel Ángel García, por ejemplo, señala “ que hay colegas que llegan a la Medicina respondiendo a un llamado de servicio a la persona enferma y que calzan con el sentido que solemos atribuir al término vocación; hay otros que llegan atraídos por la actividad y la técnica no solo avanzadas y muy prometedoras, si no que les acercan a las entrañas mismas de la vida humana, y hay médicos a los que les puede atraer la imagen 'pesuedomágica' de esta profesión y la posibilidad del reconocimiento social que otorga esta actividad". García nos advierte que la realidad se nos impone múltiple y compleja y que la Medicina como tal no puede prescindir (y no habría alcanzado, además, el papel que tiene ahora) de los médicos distribuidos en estas tres situaciones (2).

José Amador Guevara, sin embargo, advierte que quien ingresa a realizar estudios médicos pensando en la riqueza es mejor que se oriente a otras actividades, recuerda a su maestro Ignacio Chávez: "donde el negocio empieza, el decoro de la profesión acaba, cuánto diera yo porque el 
dinero no tuviera nada qué ver con la tarea profesional" (3).

En nuestro país, Alberto Perales y col. han discutido el tema. Nos hacen ver que hay una diferencia entre vocación y aptitud, entre "querer ser" y "poder ser" y puede darse que alguien que sienta el llamado desde sus entrañas no tenga las aptitudes para llegar a ser médico. Citan a Honorio Delgado cuando anota tres condiciones para llegar a ser un facultativo idóneo: vocación, aptitud y preparación fundamental (4).

A estas alturas, es legítimo plantearse una pregunta, un poco motivada por el trabajo de Perales: ¿Es la vocación un factor indispensable para ser un buen profesional médico?

Me hubiera gustado contestar que sí. Pero, ¿qué porcentaje de médicos sienten la vocación verdadera, es decir con el grado de exigencia casi religiosa que señala Gregorio Marañón? Con certeza una minoría. $\mathrm{Y}$ ¿cuántos médicos que solo tienen aptitudes y conocimiento hacen un trabajo digno y útil aliviando el dolor de un enorme contingente humano? Probablemente un porcentaje mucho mayor. $\mathrm{Y}$ debe haber también un buen número de aquellos que eligieron la profesión de Medicina porque su práctica les permite vivir holgadamente. Siempre que estos últimos puedan repetir sin avergonzarse los versos de Machado: "A mi trabajo acudo, con mi dinero pago/ el traje que me cubre y la mansión que habito, / el pan que me alimenta y el lecho en donde yago" estará bien, siempre y cuando, digo, sus honorarios sean justos y su trabajo eficiente; aunque este grupo de médicos está rozando peligrosamente con la delgada línea roja del deshumanizado mercantilismo. $\mathrm{Y}$ aquí aparece otra certeza: quienes llegan a la Medicina por vocación tienen asegurada la práctica ética de la carrera. Los otros tendrán que esforzarse más, mucho más. Y cuando se habla de ética en Medicina se incluye, obviamente, a la solvencia en la formación profesional o laboral para ser más precisos.

\section{REFERENCIAS BIBLIGRÁFICAS}

1. Garzón F. Vocación y persona. [Consultado el 1 de noviembre del 2018]. Disponible en https://docplayer.es/20047003Vocacion-y-persona-francisco-roger-garzon-

2. García M. Vocación y Medicina. Releyendo a Gregorio Marañón. AMYTIS. [Consultado el 3 de noviembre del 2018]. Disponible en https://amyts.ers/vocacion-y-medicinareleyendo-a-gregorio-maranon/

3. Guevara J. Vocación y medicina. Consultado el 4 de noviembre del 2018] Disponible en http://www.binasss.sa.cr/revistas/rmcc/rmedica/477/art1.pdf

4. Perales A, Mendoza A, Sánchez E:Vocación Médica. An. Fac. med v.74 n.2 Lima abr/jun. 2003 [Consultado el 5 de noviembre del 2018]. Disponible en hhtp://www.scielo.org.pe/scielo.php?script=sci_arttext\&=\$10 25_55832013000200009

Ángel Gavidia-Ruizª

1. Médico internista asistente del Departamento de Medicina del Hospital Belén de Trujillo y profesor asociado de Facultad de Medicina de la Universidad Nacional de Trujillo

a. Maestro en Medicina Interna 